\title{
The Role of Vocational Education And Training in Palestine in AdDressing IneQuality and Promoting Human Development
}

\author{
Randa Hilal ${ }^{a}$ \\ University of Nottingham and OPTIMUM \\ for Consultancy and Training, Palestine \\ Simon McGrath \\ University of Nottingham and University of the Western Cape
}

\begin{abstract}
UNESCO's new emphasis on vocational education and training as transformative, and concerns in particular with equity and sustainable human development, has been strongly influenced by a recent literature on VET and human development that has a particular focus on the most marginalised, especially young women, and is concerned with how their aspirations, agency and achievement of wellbeing can be promoted in the face of wide-ranging structural obstacles. This article seeks to further develop that account through an even stronger emphasis on VET in the context of extreme poverty, inequality and marginalisation as faced in Palestine. VET in Palestine serves many of the poorest and most disenfranchised in Palestinian society in a context of profound structural obstacles to wellbeing achievement. Our analysis show a very positive story of how VET has helped highly disadvantaged young Palestinians, particularly young women, to make progress on their human development.
\end{abstract}

Keywords: VET, occupied Palestinian territories (oPt), capability and functioning, human development, inequality, gender and development

\section{Introduction}

In 2012, the UNESCO-convened Third International Congress on Technical and Vocational Education and Training (TVET), in Shanghai, offered a vision of "transformative TVET" (UNESCO, 2012). At Shanghai and in the UNESCO TVET Strategy 2016-20, there is a clear sense that this transformation must include not just a focus on youth employment but also concerns with equity, gender equality, transition to green economies and sustainable societies.

This emphasis on vocational education and training (VET- our preferred term) as transformative requires a new literature that moves beyond the VET orthodoxy. This orthodoxy has focused overwhelmingly on economic and employment rationales, and has generally found VET wanting in terms of its contribution thereto (e.g., Foster, 1965; Psacharopoulos, 1981 and 1985; Psacharopoulos and Loxley, 1985; Lauglo and Lillis, 1988; Middleton, Ziderman and Adams, 1993).

In exploring our concerns with equity and sustainable human development we have been strongly influenced by the growing literature on VET and human development (e.g., Wheelahan and Moodie, 2011; Dif-Pradalier, Rosenstein and Bonvin, 2012; López-Fogués, 2012; McGrath, 2012; Powell, 2012; Tikly, 2013; Powell, 2014; Powell and McGrath, 2014; McGrath and Powell, 2015; McGrath and Powell, 2016; Dejaeghere, 2016). This literature has a particular focus on the most marginalised, especially young women, and is concerned with how their aspirations, agency and achievement of wellbeing can be promoted in the face of wide-ranging structural obstacles. Whilst

Correspondence can be directed to: rhilal@optimum.ps 
it accepts that employability is important, this literature understands this as being complex and as a means to the greater end of wellbeing.

Drawing on ongoing doctoral work by the first author, this article seeks to further develop that account through an even stronger emphasis on VET in the context of extreme poverty, inequality and marginalisation and with a theoretical influence from gender and development literature.

A paper on Palestine needs to acknowledge the question of its special status. As we shall explore in the next section, the case of Palestine is indeed an extreme one. Yet it is that which makes the case so interesting. Given the profound structural constraints under which young people navigate the Israeli-Palestinian labour market, it makes no sense to talk the conventional VET language about youth employability. Rather, the case forces us to explore how VET addresses key issues that are relevant far beyond Palestine: social justice, inequality and the achievement of economic and social rights. These are the concerns of this paper, explored through quantitative data from a larger mixed methods study.

In the next section we will outline the very particular context of Palestine. We will then move to the theoretical and conceptual toolkit used in this paper. Then we will briefly present our methodological approach. After this, we will provide an integrated presentation and discussion of our data, structured around a set of key themes that emerged from both the literature and data. We shall end with a conclusion that summarises the main messages of the paper and how it contributes to our understanding both of the Palestinian case and to wider debates about VET's contribution to addressing the challenges of poverty, unemployment and inequality, with a particular focus on gender.

\section{The Context}

Given the extreme particularities of the Palestinian case, it is extremely important to spend some time in setting the contextual scene. The very name that is in common usage to describe the territory is redolent of its unusual status: the "occupied Palestine territories" (oPt). Although this was replaced in United Nations (UN) documents in 2012 by the designation "The State of Palestine", it is clear that occupation is a continued reality and statehood an aspiration. Under the Oslo Accords, Palestine has sequentially acquired authority over policies areas such as health, education and welfare since 1993.

Figure 1. Map of the West Bank divided

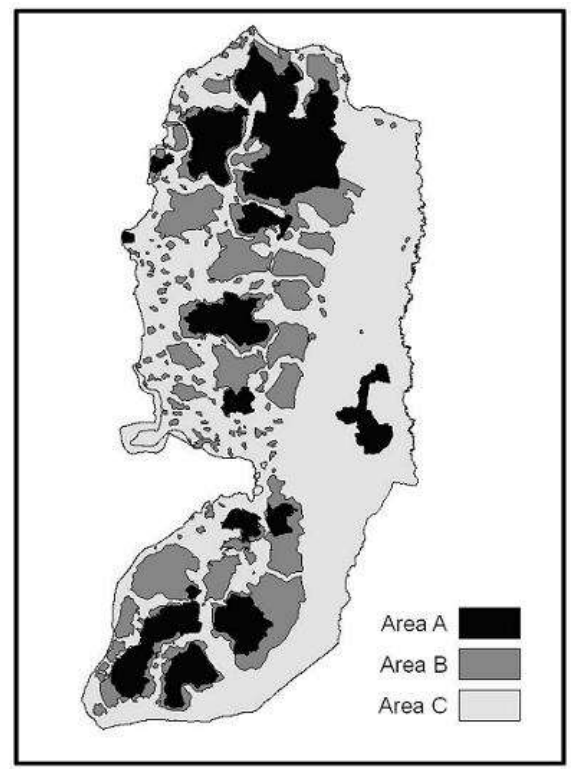

Source: UNOCHA-oPt 
However, such control is heavily circumscribed in practice, with even territorial integrity unachieved. The "Palestinian territories" are divided into three: the West Bank, East Jerusalem and Gaza, each separated from the others. Furthermore, the West Bank remains divided into externally (i.e., Israeli) designated zones, A, B and C, as shown in Figure 1 . These are not contiguous territories but reflect Israeli political considerations regarding land claims and security priorities. Over $60 \%$ of the West Bank is classed as Area C:

where Israel retains near exclusive control, including over law enforcement, planning and construction. Most of Area $\mathrm{C}$ has been allocated for the benefit of Israeli settlements or the Israeli military, at the expense of Palestinian communities. This impedes the development of adequate housing, infrastructure and livelihoods in Palestinian communities, and has significant consequences for the entire West Bank population. Structures built without permits are regularly served with demolition orders, creating chronic uncertainty and threat, and encouraging people to leave. Where the orders are implemented, they have resulted in displacement and disruption of livelihoods, the entrenchment of poverty and increased aid dependency. The humanitarian community has faced a range of difficulties in providing aid in Area $\mathrm{C}$, including the demolition and confiscation of assistance by the Israeli authorities (UNOCHA-oPt, n.d.).

Territories in Area B are subject to Palestinian civil control but Israeli military control, whilst even Area A (notionally under full Palestinian control) are subject to Israel Defence Forces raids.

The "occupied Palestinian territories" programme of the United Nations Office for the Coordination of Humanitarian Affairs (UNOCHA-oPt, n.d.) argues that this situation has resulted in a "protracted protection crisis".

Inequalities inevitably are great and the differences with Israel (with which Palestine is complexly and problematically intertwined) and between the three sub-territories are profound. Whilst Israel has high income and human development status, East Jerusalem and the West Bank are more akin to middle income countries in economic and human development terms; with Gaza is most similar to low income / low human development states in crisis. Of the 4.5 million Palestinians living within the bounds of the quasi-state, nearly $40 \%$ are defined by UNOCHA-oPt as having significant humanitarian needs, with two-thirds of these being located in Gaza. This in turn accounts for more than $60 \%$ of the population of Gaza.

Huge numbers of Palestinians are still refugees, whether within Palestine or in the neighbouring countries of Jordan, Lebanon and Syria. In 1950 these refugees numbered 750, 000; 65 years later they had risen to 5 million, more than the total population of the West Bank and Gaza. Moreover, UNOCHA-oPt characterises the whole of the populations of Gaza, East Jerusalem and West Bank Area $\mathrm{C}$ as marginalised. Additionally, the Palestinian Ministry of Social Affairs has identified a series of other groups across the oPt as marginalised, including households in poverty; women subjected to gender-based violence; female-headed households; orphans and vulnerable children; the elderly; people living with disabilities; and ex-detainees (MOSA, 2014).

Not all of Palestine's problems can simply be linked to the occupation. Traditional Palestinian gender norms act as a further constraint on young women being able to be active in the labour market and to achieve those aspects of wellbeing they most value. For many families, a women's place remains in the home and marriage is likely to put an end to working outside its walls. Official data suggests that lower female economic participation is related to various social and cultural norms and beliefs, unfavourable working conditions and the limited number of occupations accessible for women (PCBS, 2009). Moreover, public opinion survey data suggests the prevalence of a belief that women's work is secondary to men's and that a woman's main role is family caring and rearing (Alpha International, 2009). At the same time, female empowerment in other aspects of life is also constrained (Shalhoub-Kevorkian, 2004). Feminist authors have also shown how the effects of 
military occupation have exacerbated the challenges faced by Palestinian women (e.g., Giacaman and Johnson, 2002; Taraki, 2006; Muhanna, 2016).

The historic lack of a Palestinian state led to vocational education and training being dominated institutionally by non-governmental organisations (NGOs) and Church related organisations. Beginning in 1950, the United Nations Relief and Works Agency for Palestine Refugees in the Near East (UNRWA) began its mission and included VET as a vital element. The emerging Palestinian state now offers vocational education and training through the Ministry of Education, focusing on vocational upper secondary education; the Ministry of Labour, providing training for the unemployed of up to one year's duration; and the Ministry of Social Affairs, focusing on VET through rehabilitation centres for children and youth.

Efforts to unify the fragmented governance of VET in Palestine and to enhance the sector's status and quality started soon after the establishment of the Palestinian Authority in the mid1990s. This resulted in a national strategy in 1999 and an action plan in 2003. The strategy was revised in 2010, calling for quality and relevance of VET as its priority (MoE and MoL, 2010). The overall objective is to create a knowledgeable, competent, motivated, entrepreneurial, adaptable, creative and innovative workforce in Palestine. However, VET is still overburdened by external and internal challenges. The wider political situation and, in particular, the enforced limited mobility of its graduates depress employability and returns on investment in VET, whilst the policy process has not yet resulted in effective implementation, with governance still fragmented, and quality, monitoring and evaluation still weak (Hilal, 2012; Leney and Jwailes, 2014; Kuhail, 2015).

\section{Theoretical and Conceptual Framework}

The Palestinian case demonstrates the complex interactions that occur in poverty and disempowerment. Such interactions are intersectional (Davis, 1983; Crenshaw, 1989; Collins, 1990). Categories of disadvantage do not simply combine at a statistical level but are formed of a complex web of multiple identities that are structured by related systems of oppression and discrimination. According to Collins, a pattern of "interlocking oppression" is created by the interplay of culture and identity with the intersectional systems of society, such as race, gender, class, and ethnicity.

Intersectionality had its origins in the interface between black feminist academia and activism. This may help to explain why a theoretical account that could be expected at the first glance to be highly structuralist and, indeed, pessimistic is strongly concerned with optimism and offering a vision of hope for a better future.

This insistence on thinking about the dialectic potential of structure and agency is also contained within two other major influences on the approach taken in this article. The field of gender and development $(\mathrm{GaD})$ has long had concerns with intersectionality, although the language has more typically been of vertical and horizontal inequalities, that is inequalities amongst individuals and inequalities amongst groups (Stewart, 2000). However, as Kabeer (2010; 2015) notes, the language of intersectionality does sit well with much of the gender and development literature.

Kabeer $(1989$, p.10) insists on the well-established distinction between poverty as a state and as a process. As she noted early in her career,

women and men experience the state of poverty differently and often unequally and become impoverished through processes that sometimes (though not always) diverge.

One of the most important contributions of Kabeer to our thinking about poverty and inequality is her work on empowerment within the framework of GaD theory (Kabeer, 1999). She argues that empowerment is a notion that overcomes the agency-structure dichotomy by insisting on the ultimate goal of individuals being able to act as they value whilst carefully analysing the range of obstacles that limit their possibilities of achieving well-being. She suggests that processes 
of empowerment entail change at different levels and in different dimensions: change can occur at the level of the individual, in their inner sense of self or in their access to material resources; it can occur in relationships within the family and household; or it can reflect alteration in position in the wider hierarchies of the economy and state.

An emphasis on the importance of empowerment must draw us to questions of power. A range of authors have developed useful accounts of power, such as Lukes (1974) and Foucault (1982). Lukes undermined the conventional view that power is held by individuals and institutions in the material sphere only. Rather, he argued that power can be exerted by shaping what can be said and thought. Foucault took this further by moving away from the idea that such power is held by institutions and individuals, arguing instead that it is a force that flows through society and relations. This led him to reject the notion that power is something held by individuals or groups (and not others). Feminist development activists have taken these notions on further, and in our work we draw upon the four-fold model of power to, with, over and within (Kabeer, 1994; VeneKlasen and Miller, 2002).

Kabeer's notion of the "power to choose" (Kabeer, 2000) resonates strongly with the human development and capabilities approach. Sen (1999) made clear that capabilities were not simply about individual agency and freedoms, crucial though these are. Rather, he insisted that we also consider those factors that limited the ability to choose.

A growing concern for human development accounts is the likelihood of occasions when the "weight of the world" leads to a downward adjustment of preferences (Nussbaum, 2011). The language of aspirations offers a rich account of this, beginning with the work of Appadurai (2004). In his words, poverty tends to result in a "more brittle horizon of aspirations" (Appadurai 2004, p.69) for individuals and communities so that they cannot imagine, let alone achieve, what might be possible in other circumstances.

Thus, a "capability to aspire" (Powell, 2012; McGrath and Powell, 2015) is essential if other capabilities are to be realised. This account has been developed usefully through a number of empirical studies from Africa, by Ibrahim (2011) on Egypt, by Conradie and Robeyns (2013) and Powell $(2012 ; 2014)$ on South Africa, and by Dejaeghere and Baxter $(2014 ; 2016)$ on Uganda and Tanzania. Conradie and Robeyns (2013) argue that if people have low aspirations, then they may believe that certain capabilities are unavailable even if they are achievable, if only implausibly. They note that the central capabilities of expanding "people's beings and doings that they have reason to value" is challenged by a deflation of aspirations caused by adaptive preferences:

But the valuation process is vulnerable to people's adaptation to adverse circumstances: if people have limited ambitions, wishes or preferences, then they will be very modest when they formulate which capabilities they find valuable. The same applies to aspirations: if people have adapted aspirations, they will only have modest goals, ambitions, and hopes, even if there are much more valuable options open to them. (Conradie and Robeyns 2013, p.566)

In work from Egypt, Ibrahim (2011) argues that there is a cyclical relationship between poverty and failed aspirations. She shows how the two most unfulfilled capabilities of poor people in Egypt were decent work and decent education, and how these were mutually reinforcing, across generations. Educational failure undermined the communication skills and access to information of poor people. This in turn prevented them from achieving their job aspirations, something that was also undermined by poverty, high levels of unemployment, nepotism and asymmetrical labour market information. Failed aspirations for decent work undermined income, the ability to play a full role in the community, business start-up opportunities and marriage prospects. In the next generation, access to decent schooling and health were undermined, starting a new spiral of aspiration deflation.

However, a more positive story is told in literature from sub-Saharan Africa. Conradie and Robeyns, Dejaeghere and Powell suggest that development interventions can make a positive difference in this aspirational space. Powell's research with public TVET college students in Cape Town found that their experience at the college had helped many of them develop a new sense 
of who they could be and provided the impetus for them to develop larger aspirations. This, she argues, is a key potential role for formal education providers (Powell, 2012). Working in the same location, Conradie and Robeyns also point to the transformational possibilities of interventions that build aspirations. They note the importance of capability obstacles, barriers to successful conversion of resources into capabilities. In their case, these included inadequate income, lack of supportive organisations, an unhelpful state, conflict, cultural norms and education (Conradie and Robeyns 2013, p.570). These obstacles act in large part through their reduction of aspirations. Thus, to achieve capabilities, it is necessary to overcome capability obstacles. Conradie and Robeyns suggest that aspirations can play at least two roles here: a capabilities-selecting role and an agency-unlocking role (Conradie and Robeyns 2013, p.559).

Moreover, aspirations do not simply lie dormant within people, waiting to be activated. Rather, they come into existence through the process of exploring them. Thus, it makes little sense to think about aspirations in the abstract or see them as stable. Instead, they are dynamic, potentially both built from wide and positive experiences but also created in respect to goals that appear untenable from where a person finds themselves at present. Even then, they require some spark, such as the ability to see or read about others who have an apparently better life. In the Palestinian case, the proximity of Israel and illegal settlers within Palestine is likely to be pertinent here.

For Dejaeghere (2016), aspirations and agency are situated within a dialectic tension within structures that both constrain and offer possibilities. In contrast with Ibrahim's story of an intergenerational downward spiral, Dejaeghere focuses on sites of possibility where better futures can be imagined. She argues that this makes it possible for aspirations to result in agency. In her view, a crucial aspect of identifying capabilities and achieving functionings begins with an ability to "see the future".

Thus, the study seeks to integrate accounts of gender and development, and linked arguments about intersectionality, with a human development account in exploring the important ways in which VET supports the life chances of marginalised young people. This offers a new enrichment of the VET and human development account by making its gender analysis more robust.

\section{Methodology}

This article reports on part of the data and analysis of a larger, ongoing doctoral project. For the larger project, a combination of qualitative and quantitative methods was used. Data was collected using a VET graduate survey, interviews, focus group discussions, case studies of key VET institutions and a review of available documents. However, this article focuses on the data from the survey.

This survey was conducted between January and July 2015 and included a representative sample of 2,011 graduates, from 31 VET institutes constituting the main governmental and nongovernmental VET providers. These graduates were surveyed four years after graduation to measure the longer-term impact of their education. 764 questionnaires were filled, giving a response rate of $38 \%$, which was considered more than adequate. Twenty nine (29) percent were females and $71 \%$ male, reflecting the representation of females in VET institutes, of which $16 \%$ were from Gaza, $7 \%$ Jerusalem and the $76 \%$ from the West Bank. The sample from Gaza is unrepresentatively small due to difficulties of surveying in Gaza.

The survey contained a series of questions about socio-economic status, education and impacts of the wider political situation. These were followed by questions that explored various aspects of what we considered to be major possible impacts of VET. These included labour market transitions; ability to contribute to household income; empowerment; and capability identification and functioning achievement. The survey concluded with an exploration of the structural obstacles to wellbeing. Key concepts were operationalised into a set of statements to be rated on a fivepoint Likert scale. Percentages in Figures 2 and 5 below are calculated by aggregating responses of "satisfied" and "highly satisfied" on these scales. The data generated was analysed using the SPSS 
software package, informed by the theoretical framework of the larger study. Data in Figures 3 and 4 below are compared with official statistical data as a means of benchmarking findings.

\section{The Effects of VET on Those Experiencing Intersectional Poverty and Inequality}

\section{VET Graduates are Predominantly from the Most Impoverished and Disempowered Backgrounds}

Although not exclusively, the VET system caters for those who have performed less well in the school system. Inevitably, performance here is closely related with socio-economic status. It is not surprising, therefore, that VET graduates are largely from poor and disempowered backgrounds, with many impoverished and disempowered as a result of the occupation. According to the survey data, $66 \%$ of the VET graduates came from families that were under the national poverty line when they enrolled, as opposed to the national figure of $26 \%$ of households living in poverty found in national statistics for the year that they enrolled (PCBS, 2012). In Gaza, this rose to 93\%. Overall, $50 \%$ were considered to be in "deep poverty" (calculated as less than US Dollars 1.40 per day in 2010). This was almost double the national average. Moreover, more than two-thirds displayed clear intersectional effects, such as coming from large families, having family members living with disability and/or chronic disease. Across indicators, female graduates were on average from families with greater poverty and marginalisation.

The impacts of poverty and inequality in Palestine are profoundly shaped by spatial effects, which are, in turn, deeply inscribed with the effects of the occupation. As Figure 1 above illustrates, those living in the West Bank are all affected by the occupation, although differentially according to which zone they live. Movement between the fragments of the zones, into and out of East Jerusalem, and across into Israel are all constrained and complicated by numerous checkpoints, which may be closed according to Israel's strategic concerns. As has been well-publicised, Gaza is effectively under siege, cut off from almost any movement into Israel or Egypt.

The occupation's direct and indirect effect on the impoverishment and further marginalisation of the VET graduates families is strongly spatially influenced. Overall, 1 in 5 graduates' households were directly affected by the context of occupation, but this became more than 1 in 4 for those living in Jerusalem outside the Wall and, 1 in 3 for those living adjacent to the Wall. Graduates indicated how they were affected, including: loss of land (24\%), loss of residence (7\%), loss of livelihood system (45\%) and loss of water/ other resources (3.4\%). Other effects included the siege of Gaza, the overall worsened economic situation affecting their work, the lack of permits for work, and the existence of a gate to their community. Moreover, $46 \%$ of the sample were refugees, against a national average of 43\% (PCBS, 2016), with two-thirds in Gaza having refugee status, while $14 \%$ lived in refugee camps.

Marginalisation also comes from negative experiences of the formal education system and from the differential status of different aspects of the lifelong learning system. More than two-third of the graduates had low grades when enrolling at VET institutes, and some had failed their previous grade, which would not allow them to continue their academic studies after the $12^{\text {th }}$ grade national examinations, hence would be drop-out or potential drop-out of the system, as students cannot progress to higher education without passing the $12^{\text {th }}$ grade national exam (the Tawjihi) and if they leave the general academic streams, they have inadequate skills for work.

Previous academic performance is likely to be a factor in over $80 \%$ reporting that they preferred practical training to academic studies although it is important to remember the common correlation between poverty and academic performance. Poverty loomed large in choices to pursue vocational programmes, something that human capital accounts are poor at capturing. Over two-thirds reported that their choice was influenced by the affordability of VET as compared to higher education; whilst $82 \%$ reported wanting to join the labour market as quickly as possible to support their families. The latter rationale was even stronger amongst female graduates, $88 \%$ of whom reported wanting rapid labour market insertion. 
Inevitably, there is a hierarchy of status of vocational providers. Institutions under the Ministry of Education had the smallest proportions of graduates from poor backgrounds and the highest numbers who saw vocational education as a pathway to higher education. Those who studied within the Ministry of Social Affairs sub-system were the poorest and most marginalised across a range of indicators, with UNRWA and NGO systems also appearing to be particularly common routes for the poor. UNRWA targets refugees and it was noticeable that proportions of refugees were much lower in institutions under the Ministries of Education or Labour.

\section{Moreover, They Experience Many Structural Obstacles to Achieving Their Wellbeing}

Graduates reported experiencing multiple effects of these structural factors as affecting their wellbeing. First, they noted that the context of the occupation is a massive obstacle to the achievement of valued functionings and hence wellbeing. The onerous security checks and limits on travel between areas seriously undermined graduates' ability to secure decent work and generate income. Incomes were further depressed by the costs that were added to travel, and the general cost of living in Palestine is inflated by blockades, most especially in Gaza. The history of military occupation has seriously undermined economic growth and, as reported above, the data shows that the majority of graduates had seen their family livelihood assets reduced. Personal, household and community resilience were all reported to have been threatened.

Second, the Palestinian economy is underperforming for internal as well as external reasons. The unequal linkage of the Palestinian and Israeli economy is a problem that inflames the cost of living problem. Domestically, economic policy is weak and implementation and enforcement weaker still. Wages within Palestine remain low, but opportunities to travel into Israel for higher wages are limited and subject to sudden freezes. Some graduates reported earning under the legal Palestinian minimum wage.

Third, graduates made clear that traditional Palestinian gender norms still restricted women's empowerment. The widespread continuation of old views of the expected role of women in the household limited female economic and social participation. Many female graduates know that marriage is likely to mark the end of their paid work in the face of husbands' and in-laws' expectations that wives will restrict their activities to the domestic sphere. Although these graduates were demonstrating far higher levels of labour market participation than the national gender norms, there was a strong sense that the independence gained was under constant familial and societal threat.

Fourth, institutional and national policy frameworks and the legislative system undermine the benefits of VET. The Palestinian Authority policies on employment do not confer any recognition to vocational qualifications and universities largely do not recognise these qualifications either. There is institutional and policy fragmentation in the VET sector and plans for reform remain largely unimplemented.

Fifth, VET still suffers from the exclusionary effects of negative public attitudes. Of the graduates, $24 \%$ stated that local community perceive VET negatively, as male-oriented and for low achievers. A similar proportion felt that employers discriminated against VET graduates. Even amongst the VET graduates surveyed, such negative attitudes were evident, with one-in-six reporting their own negative perceptions. However, we need to remember that this contrasts with $59 \%$ of the graduates perceiving VET positively. Particularly valuable were its contribution to employment and economic returns; and its provision of life skills and employability skills.

\section{Yet, Graduates Hoped for Much from VET: Aspirations of the VET Graduates}

In the face of these major structural obstacles, what is most striking from our data is that our respondents had strong aspirations. Graduates were asked to rate a series of 13 possible areas of capabilities that they had hoped to achieve after graduation, the areas being drawn from the existing literature on capability lists constructed in somewhat similar settings. The percentages presented 
below indicate that these items were agreed to be valued capabilities The findings are presented in Figure 2.

Figure 2. Expressed capabilities of youth upon graduation from VET

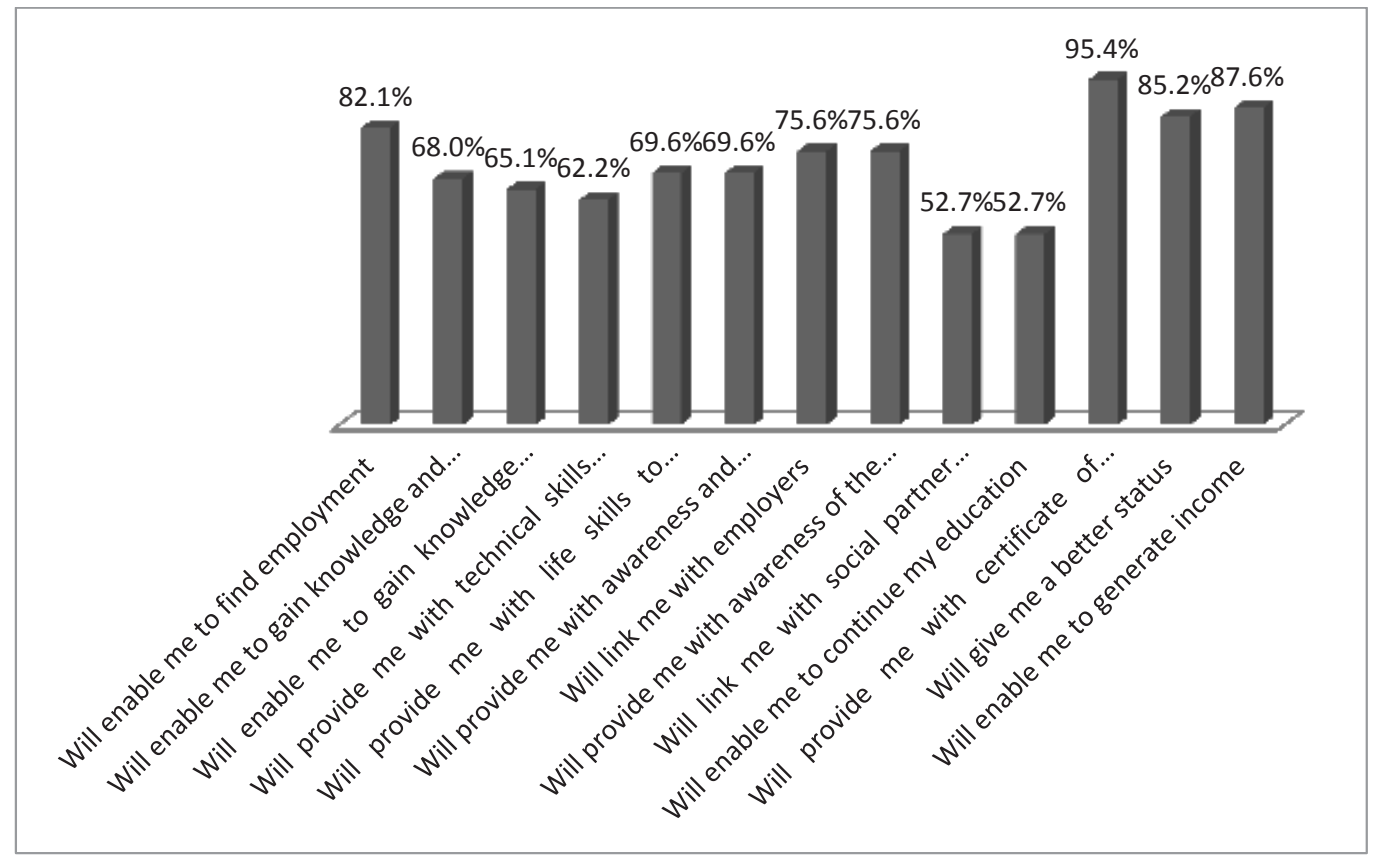

Source: PhD Survey data

The most valuable element for them was certification. This may seem surprising but certification has very important status value in a society where credentials are important, building self-worth and employability, as well as enhancing the possibility of progressing to higher education, which itself was valued as an important outcome by more than half those sampled. An improvement in personal status was the third highest ranked capability ( $85 \%$ identified this). Understandably, the capability to generate income ranked very highly ( $88 \%$ aspired to this). Employment-related aspects rated as important to at least two-thirds of those surveyed, reinforcing the importance of traditional notions of skills for employability. The acquisition of life and entrepreneurship skills were somewhat lower priorities, but still important for the majority of those surveyed.

The following sections will explore the achievement of important elements of these aspirations both in terms of objective measures of this achievement and the perceptions of the respondents.

\section{They Perform Well in Labour Market Transitions: Graduate Labour Market Participation and Unemployment}

In spite of their largely disadvantaged backgrounds and the intersectional nature of many respondents' experiences of poverty and marginalisation, those graduates surveyed appeared to have benefitted from their participation in vocational education and training in terms of their employment status. This suggests that their aspirations were, at least partially, well-founded. 
We look at two measures here: first, the labour force participation rate (LFPR), which measures those who report themselves to be employed or actively seeking employment. Figure 3 summarises this data, disaggregated by gender, refugee status and location, and compared to the overall national labour force participation rate (LFPR) and the national youth LFPR at the time of survey. LFPR is important partly in giving a sense of those who are "discouraged" from seeking work due to their perceived lack of employment prospects. Second, we consider unemployment rates (Figure 4 below), a more stringent measure of labour market transition.

Figure 3. VET graduates LFPR in comparison with national figures for all of working age and national youth figures

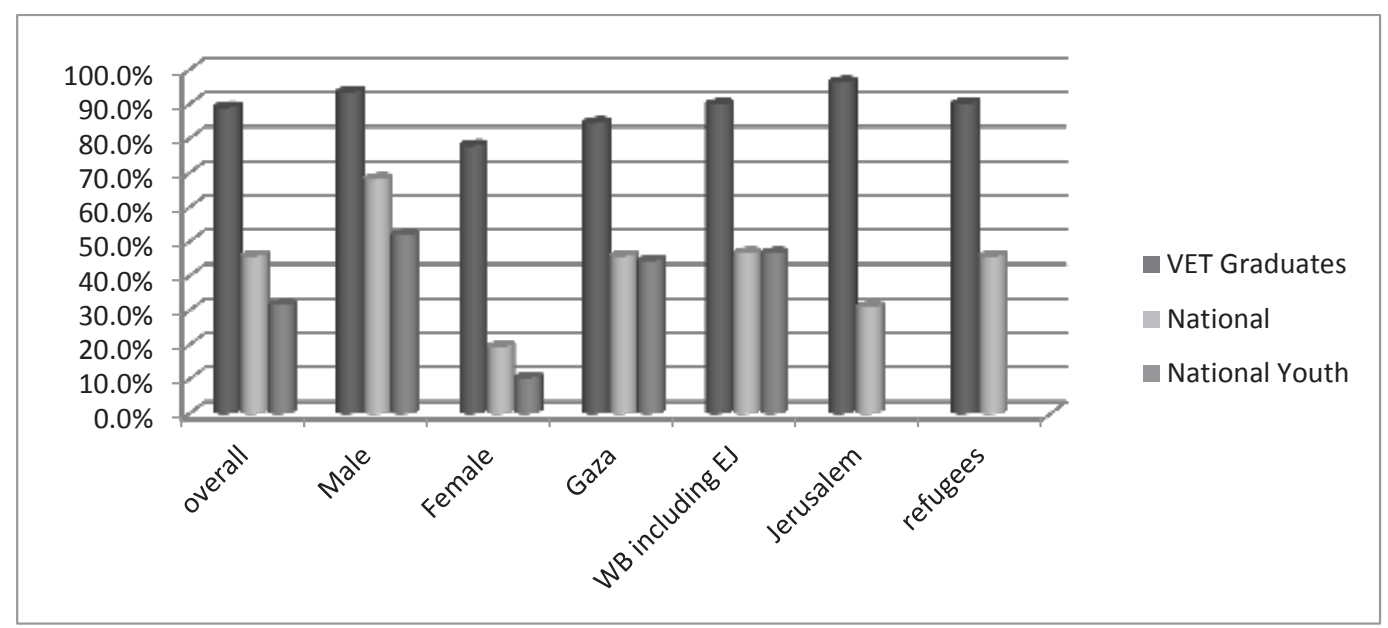

Sources: PhD survey and PCBS data

The headline figure here is that the LFPR of $89 \%$ for the surveyed youth was nearly double the adult LFPR (46\%) and triple that of the youth cohort (age 18-24-32\%) nationally. This is remarkable but the statistics for the young women sampled are even stronger: $78 \%$ were participating in the labour force, as opposed to less than $10 \%$ of their age cohort. These figures confirm previous studies and findings in the field (Hilal, 2009 and 2012; MAS-PCBS-PMA, 2009) and are also in line with previous studies indicating the high demand for VET graduates from the labour market (Hilal, 2010; 2013). The high LFPR for female VET graduates is comparable to higher education data. It appears that many families are interested in young women participating in the labour force. Nonetheless, for those who were not participating in the labour force, the reasons given were highly gendered: approximately half of male respondents (46\%) were studying; approximately half of female respondents (53\%) cited household responsibilities, whist another $24 \%$ of young women cited parental or spousal objections to employment outside the household. Whilst VET participation does appear to be possible for a group of young women who are largely able to transform this into labour force participation, these figures suggest that approximately one-quarter of sampled young women entering VET were not able to convert participation in VET programmes into labour market participation. It appears that these young women were able to aspire to labour market participation and had the agency to acquire vocational education and training but were unable to overcome structural factors, including patriarchy, in order to convert what they valued into achieved improvements in their wellbeing. 
Figure 4. VET graduates unemployment rates in comparison with national figures and national youth figures

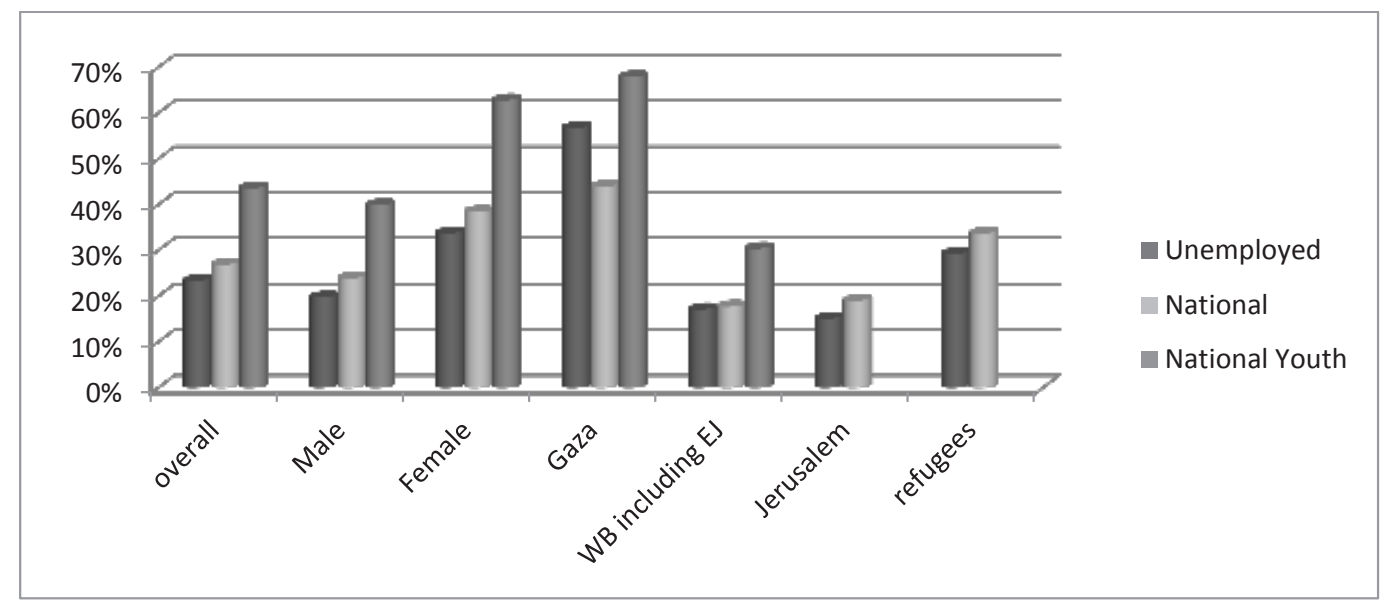

Sources: Hilal's doctoral survey and PCBS data

Of course, labour market participation itself does not simply result in achieved employment, let alone decent work or the wellbeing improvements that are presumed to flow from this. At the time of the survey, Palestine had a youth unemployment rate of $41 \%$, rising to $61 \%$ for females. More than two-thirds of youth in Gaza were unemployed. The sampled VET graduates performed better than the national youth averages across categories. Overall, they were half as likely to be unemployed as their peers, and this benefit was consistent for both genders. Moreover, even amongst those who were unemployed at the time of the survey, $75 \%$ reported having been employed previously.

However, the employment benefits of VET were much more apparent in the West Bank and East Jerusalem than in Gaza. Faced with the overall unemployment crisis in Gaza, the sample were only 10 percentage points better off than their age cohort on this indicator. Nonetheless, given that those surveyed were more likely to be poor and marginalised than the national averages, these findings are impressive.

We surveyed graduates four years after course completion as we were mindful of the often long delays in securing employment. However, $62 \%$ had found employment within six months of graduation and $79 \%$ within a year. Again, this is impressive when compared with other data. For instance, the International Labour Organisation (ILO) found that the mean unemployment period for Palestinian youth on leaving full-time education and training was 19.5 months (Sadeq and Elder, 2014). When the constraints acting upon our sample are remembered, it appears that these findings are very positive. They point to the possibility of VET playing a very powerful role in supporting the process of wellbeing achievement of highly vulnerable young people, particularly young women.

This comparative success in labour market insertion is mirrored in other variables that show that the benefits are shared with others. Of the sample, 58\% reported that they were contributing to their family's income, with $26 \%$ contributing more than a quarter of their household's income. Additionally, 51\% reported that their family had improved their income status compared to when they enrolled in the VET institution. However, this benefit was less apparent for those living in marginalised areas and amongst the poorest. Under $25 \%$ of those living in Gaza had seen household income benefits, as compared to over $50 \%$ in other areas. Only $23 \%$ of the very poorest had seen household income security improve since enrolment, as opposed to $58 \%$ in the wealthiest group. Moreover, it was almost twice as common for male graduates to be contributing to family income than was the case for females (65\% to $38 \%$ ). Remembering that in the human development account 
vocational education is about supporting the wider life plans of learners, it is striking that one-fifth of graduates had set up new families.

\section{Moreover, Social Empowerment Indicators for the VET Graduates are High}

The human development approach insists that VET is not just about the labour market. Given our concerns with empowerment, graduates were asked to rate their empowerment through VET across 21 elements reflecting aspects of power within, power to, power with and power over. The following figure shows percentages of respondents who reported being satisfied or highly satisfied for each aspect of power.

Figure 5. Percentages of VET graduates agreeing to social empowerment change indicators

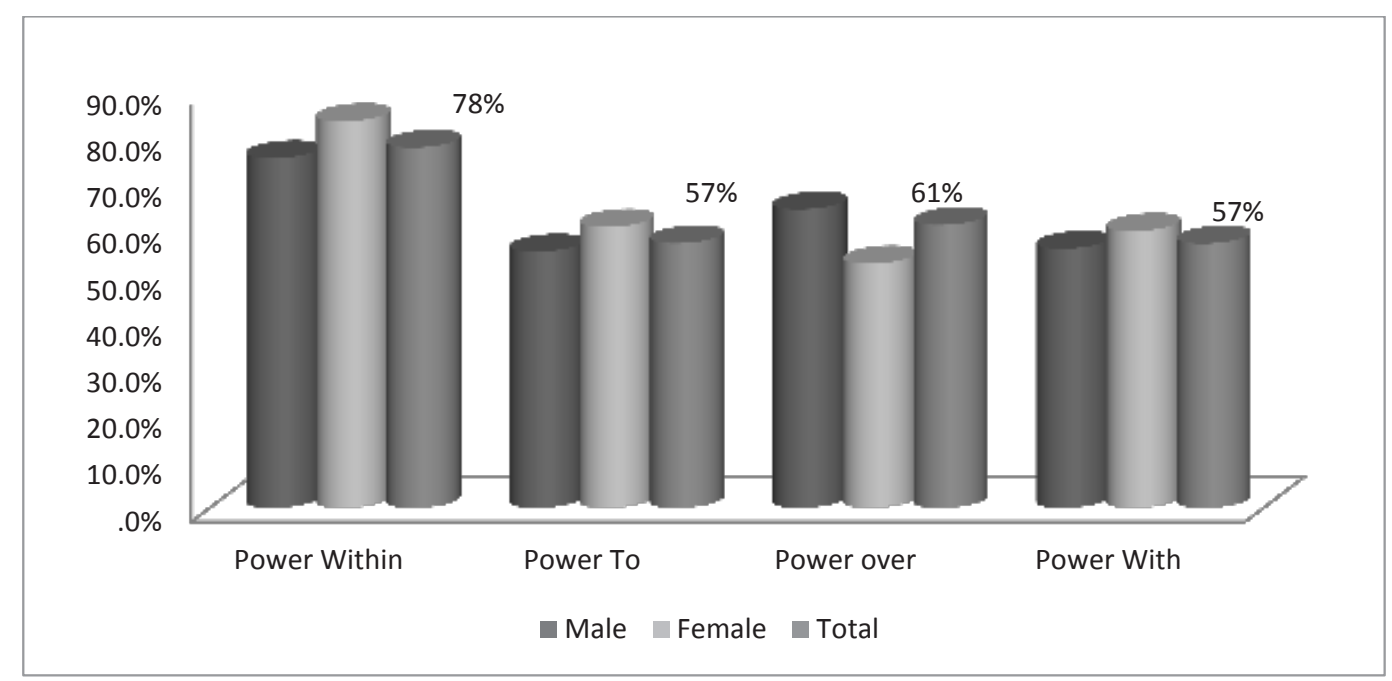

Source: Survey data

The results suggest that the surveyed graduates generally feel relatively empowered. The lowest scoring category, "power to" is concerned with aspects of empowerment with respect to family decision-making, including sharing domestic labour. That there is actually a slightly more positive female response here may indicate that continuing challenges with the highly patriarchal nature of Palestinian society are experienced alongside other forms of unequal power such as age hierarchies. To be young is to be relatively disempowered in household decision-making, whether male or female. The highest ratings on empowerment relate to aspects of self-confidence under the "power within" category. This needs further exploration through the qualitative data but it may be that VET institutions are playing a role here in building the self-confidence and empowering of young people and hence are preparing them to enhance their well-being through aspirations and agency, as Powell $(2012 ; 2014)$ and Dejaeghere (2016) found in South Africa and Tanzania. Moreover, the findings appear to point in the same direction as Conradie and Robeyns (2013) in building these young people's ability to unlock agency and, in the case of young women, to select employment as something they value in the face of societal obstacles. As we noted above, Dejaeghere understands aspirations and agency as existing in dialectic tension with structures that both constrain and offer possibilities. Her suggestion that a crucial aspect of identifying capabilities and achieving functionings begins with an ability to "see the future" seems pertinent here. 
Again, it is noteworthy that the surveyed VET graduates display a slight gender difference in response here with more positive female responses. Given the effects of gender injustice, this may also point to an important positive effect of VET institutions in promoting social justice, a finding that resonates with the authors cited in the previous paragraph.

The one dimension on which female graduates are less positive than their male counterparts is "power over", areas that reflect control over engagement with the world-of-work and wider life (such as choices about marriage and place to live). As we have already seen, female access to the labour market is significantly less than male, so such a finding is not surprising, suggesting the gender-based social constraints when it comes to decision making of choices related to their lives. As regards locational effects, those living in refugee camps report the lowest levels of empowerment.

As the literature on VET and human development makes clear, it is one thing to identify a series of things to value from vocational education and another thing to achieve these. If the bulk of the popular and academic literature about VET was to be believed, then we would expect very low levels of conversion of these capabilities into functionings, VET having widely been derided as a second class learning system. Yet, overall, $80 \%$ of graduates reported at least a $50 \%$ conversion rate, and $42 \%$ reported more than $75 \%$. What is most striking in this aspect is that those from poorer and more disadvantaged backgrounds reported stronger conversion rates. Those reporting $75 \%$ or more conversion rose to $46 \%$ for the poor; $50 \%$ for those in deep poverty; and $64 \%$ for those living in Gaza. There were slightly higher female levels of reported meeting of expectations.

\section{Conclusion}

VET in Palestine serves many of the poorest and most disenfranchised in Palestinian society in a context of profound structural obstacles to wellbeing achievement. These obstacles are inextricably linked to the continued occupation and the 70 years of refugee status endured by millions of Palestinians. Moreover, for young Palestinian women in particular there are also cultural norms that constrain aspirations, agency and the achievement of wellbeing.

The quantitative data is in need of further analysis alongside the qualitative data, which was collected subsequent to the survey. Nonetheless, it appears to show a very positive story of how VET has helped highly disadvantaged young Palestinians, particularly young women, to make progress on their human development. An important step towards achieving improved wellbeing comes from being able to gain certification and become active in the labour market. For the latter, a participation rate triple that of the wider youth cohort is impressive, but nothing to the nearly eight-fold benefit for young women compared to their non-VET peers. As we noted above, it is important to turn labour force participation into employment. There is a sizeable gap here, unsurprisingly. Nonetheless, VET graduates of both sexes were half as likely to be unemployed than their peers. The benefits of this were seen in terms of personal and household income. A sizeable number of young people gained the financial resources to get married, whilst others noted a range of benefits in terms of aspirations and their achievement.

As far as the wider literature on VET is concerned, this article adds weight to the human development arguments about the inadequacy of the human capital account. Whilst the human capital argument stands to the extent that young people and their families are investing in their education and training in the hope of higher incomes, it focuses too simplistically on labour market outcomes and ignores both the structural obstacles to achievement and the wider human goals that vocational learners possess (e.g., Powell, 2014; McGrath and Powell, 2015).

Rather, our account reinforces the human development account by building on existing work that has argues that VET graduates are not simply motivated by a desire to secure paid work (LopezFogues, 2012; Powell, 2012; 2014). Whilst this is a very important capability, it stands in a complex relationship with a wider set of life outcomes that are of value to VET graduates. The evidence here that VET is serving many of the most marginalised and is successfully advancing their aspirations, agency and the achievement of wellbeing supports Powell's claims about the possibilities of thinking 
about VET institutions as key agents of human development advancement and reinforces her propoor claims for such institutions (Powell, 2014). The advancement towards achievement of their wellbeing, gaining control over resources, achieving certain degrees of empowerment and the change of some power relations within the household and the community had a valuable effect on reducing inequality. Nonetheless, these gains are fragile and are still challenged by structural obstacles and societal attitudes, some of which would require institutional and policy related actions in order to convert aspirations into achievement, which we will discuss in further work.

Moreover, this paper takes further the increasing explicitly feminist tone of much of the skills for human development literature by giving more explicit attention to GaD. Whilst Dejaeghere, cited elsewhere in this paper, has recently made an important step of linking GaD and human development (Dejaeghere, 2015), this was for general education rather than VET. The VET-specific argument about gender and human development is an area in which further work is needed, particularly in building in insights from feminist economics (cf. McGrath, 2012) but we believe we have made a contribution here.

We believe also that the Palestinian case provides a far richer sense of the multi-dimensional poverty, inequality and disempowerment experienced by many of those accessing VET than has been presented thus far in the human development and VET literature. This is an even more challenging situation than existed in South Africa (Powell, 2012; 2014) or Spain (Lopez-Fogues, 2012) after the global crash. This makes even clearer the power of a human development account of VET that stresses agency and structure and which is profoundly concerned with the need to support both the expansion of aspirations and the successful conversion of capabilities into functions (cf. Dejaeghere and Baxter, 2014; Dejaeghere, 2016). The case illustrates that this perspective makes sense when thinking about those who are very poor and highly constrained by structural factors. Indeed, we argue that it is precisely in thinking about skills development that can counter social injustice, gender violence and multidimensional poverty and marginalisation that a critical human development approach has most potential.

\section{References}

Alpha International (2009). A Public Opinion Survey on Palestinian's Attitudes Towards Women's Labour Force Participation. Ramallah: Palestinian Women Research and Development Center. Appadurai, A. (2004). The capacity to aspire. In V. Rao and M. Walton (Eds.), Culture and Public Action. Stanford: Stanford University Press, pp. 59-84.

Collins, P. (1990). Black Feminist Thought. New York: Routledge.

Conradie, I. and Robeyns, I. (2013). Aspirations and human development interventions. Journal of Human Development and Capabilities, 14(4), pp. 559-580.

Crenshaw, K. (1989). Demarginalizing the intersection of race and sex. Chicago Legal Forum, 1(8), pp. 139-167.

Davis, A. (1983). Women, Race and Class. New York: Vintage.

Dejaeghere, J. (2015). Reframing gender and education for the post-2015 agenda. In S. McGrath and Q. Gu (Eds.), Routledge Handbook on International Education and Development. Abingdon: Routledge, pp. 63-77.

Dejaeghere, J. (2016). Girls' educational aspirations and agency. Critical Studies in Education, pp. 1-19. doi:10.1080/17508487.2016.1188835.

Dejaeghere, J. and Baxter, A. (2014). Entrepreneurship education for youth in sub-Saharan Africa. Progress in Development Studies, 14(1), pp. 61-76.

Dif-Pradalier, M., Rosenstein, E. and Bonvin, J.M. (2012). Vocational training as an integration opportunity for struggling young adults? A Swiss case study. Social Work and Society, 10(1), pp.1-16.

Foster, P. (1965). The vocational school fallacy in development planning. In C. Anderson and M. Bowman (Eds.), Education and Economic Development. Chicago: Aldine, pp. 142-167.

Foucault, M. (1982). The subject and power. Critical Inquiry, 8(4), pp. 777-795. 
Giacaman, R. and Johnson, P. (2002). Characteristics of head of household, household composition, and household labour pattern. In R. Giacaman and P. Johnson (Eds.), Inside Palestinian Households. Vol. 1. Bir Zayt: University of Birzeit, pp. 47-60.

Hilal, R. (2009). Vocational education and training for women in Palestine: Impact on access to employment. Paper presented to Second TVET conference, Nablus, 20 April.

Hilal, R. (2010). Quantitative and Qualitative Training Needs Assessment of Work Force Within the Basic Work Levels. Ramallah: MOEHE and BTC.

Hilal, R. (2012). Vocational education and training for women and youth in Palestine. International Journal of Education Development, 32(5), pp. 686-695.

Hilal, R. (2013). Labour Market Survey: Training needs and VET relevance gaps analysis. Ramallah: MOEHE and BTC.

Ibrahim, S. (2011). Poverty, aspirations and wellbeing. SSRN Electronic Journal. doi: 10.2139/ ssrn.1747798

Kabeer, N. (1989). Monitoring Poverty as if Gender Mattered. IDS Discussion Paper 255: University of Sussex.

Kabeer, N. (1994). Reversed Realities. London: Verso.

Kabeer, N. (1999). Resources, agency, achievements. Development and Change, 30(3), pp. 435-464.

Kabeer, N. (2000). The power to choose. London: Verso.

Kabeer, N. (2010). Can the MDGs Provide a Pathway to Social Justice? Brighton: IDS/UN MDG Achievement Fund.

Kabeer, N. (2015). Gender, poverty, and inequality. Gender and Development, 23(2), pp. 189-205.

Kuhail, H. (2015). Implementing the TVET Strategy (in Arabic). Ramallah: Palestine Economic Policy Research Institute.

Lauglo, J. and Lillis, K. (Eds.) (1988). Vocationalising Education. Oxford: Pergamon.

Leney, T. and Jwailes, Z. (2014). Mapping Vocational Education and Training Governance in Palestine. Turin: European Training Foundation.

López-Fogués, A. (2012). Theorising Further Education Through a Capability Lens: Vulnerability and freedoms. Jubilee Working Papers, School of Education: University of Nottingham.

Lukes, S. (1974). Power. Basingstoke: Macmillan.

MAS-PCBS-PMA. (2009). The Economic and Social Monitor 17. Available at http://www.pma.ps/ Portals/1/Users/002/02/2/Publications/English/Quarterly\%20Reports/Economic\%20Monitors/ Economic_Monitor_17_EN.pdf [Accessed 1 September 2016].

McGrath, S. (2012). Vocational education and training for development. International Journal of Educational Development, 32(5), pp. 623-631.

McGrath, S. and Powell, L. (2015). Vocational education and training for human development. In S. McGrath and Q. Gu (Eds.), Routledge Handbook on International Education and Development. Abingdon: Routledge, pp. 276-288.

McGrath, S. and Powell, L. (2016). Skills for sustainable development. International Journal of Educational Development, 50, pp. 12 -19.

Middleton, J., Ziderman, A. and Adams, A. (1993). Skills for Productivity. Oxford: Oxford University Press.

Ministry of Education, Ministry of Labour (2010). Winning for a Future, Chances for Our Youth. Ramallah: Palestine Authority.

Ministry of Social Affairs (2014). The Social Protection Sector Strategy 2014-2017. Ramallah: Palestine Authority.

Muhanna, A. (2016). Agency and Gender in Gaza. London: Routledge.

Nussbaum, M. (2011). Creating Capabilities. Cambridge MA: Harvard University Press.

Palestinian Central Bureau of Statistics (2009). Market Factors That Discourage Women From Joining the Labour Market. Ramallah: PCBS.

Palestinian Central Bureau of Statistics (2012). Living Standards in the Palestinian Territory. Ramallah: PCBS.

Palestinian Central Bureau of Statistics (2016). Labour Force Survey: Annual Report 2015. Ramallah: PCBS. 
Powell, L. (2012). Reimagining the purpose of VET. International Journal of Educational Development, 32(5), pp. 643-653.

Powell, L. (2014). Reimagining the Purpose of Vocational Education and Training: The perspectives of further education and training college students in South Africa. Unpublished PhD thesis: University of Nottingham.

Powell, L. and McGrath, S. (2014). Advancing life projects. Journal of International and Comparative Education, 3(2), pp. 2-13.

Psacharopoulos, G. (1981). Returns to education: An updated international comparison. Comparative Education, 17(3), pp. 321-341.

Psacharopoulos, G. (1985). Returns to education: A further international update and implications. Journal of Human Resources, 20(4), pp. 583-604.

Psacharopoulos, G. and Loxley, W. (1985). Diversified Secondary Education and Development. Baltimore: Johns Hopkins University Press.

Sadeq, T. and Elder, S. (2014). Labour Market Transitions of Young Women and Men in the Occupied Palestinian Territory. Geneva: Youth Employment Programme, Employment Policy Department, International Labour Office.

Sen, A. (1999). Development as Freedom. Oxford: Oxford University Press.

Shalhoub-Kevorkian, N. (2004). Racism, militarisation and policing. Social Identities, 10(2), pp. 171-193.

Stewart, F. (2000). Crisis prevention. Oxford Development Studies, 28(3), pp. 245-262.

Taraki, L. (Ed.) (2006). Living Palestine. Syracuse: Syracuse University Press.

Tikly, L. (2013). Reconceptualising TVET and development. In UNESCO-UNEVOC (Eds.), Revisiting Global Trends in TVET. Bonn: UNESCO-UNEVOC, pp. 1-39.

UNESCO (2012). Transforming Technical and Vocational Education and Training. Paris: UNESCO.

UNOCHA-oPt (n.d.). About us. Available at: https://www.ochaopt.org/page/about-us. [Accessed 1 September 2016].

UNOCHA-oPt (n.d.). Area C. Available at: https://www.ochaopt.org/location/area-c. [Accessed 1 September 2016].

VeneKlasen, L. and Miller, V. (2002). A New Weave of Power. London: Practical Action Publications. Wheelahan, L. and Moodie, G. (2011). Rethinking Skills in Vocational Education and Training: From competencies to capabilities. Darlinghurst: New South Wales Board of Vocational Education and Training. 